\title{
GARLIC EXTRACT EFFICACY AGAINST THE VIABILITY OF ENTEROCOCCUS FAECALIS (IN VITRO)
}

\section{ANDRIANI OCTAVIA, SARWORINI BAGIO BUDIARDJO*, IKE SITI INDIARTI, EVA FAUZIAH, MARGARETHA SUHARSINI, HERIANDI SUTADI, MOCHAMAD FAHLEVI RIZAL}

Department of Pediatric Dentistry, Faculty of Dentistry, Universitas Indonesia, Jakarta 10430, Indonesia. E-mail: sarworinibagio@yahoo.com

Received: Sept 13, 2018, Revised: Dec 10, 2018 and Accepted: Feb 8, 2019

\begin{abstract}
Objective: Enterococcus faecalis, Gram-positive facultative anaerobe capable of invading the dentinal tubules, is resistant to several irrigating solutions and intracanal medications. Motivated by the antibacterial effect exhibited by garlic extract against a wide variety of Gram-positive and Gram-negative bacteria, as well as anaerobic bacteria such as Lactobacillus and E. faecalis, we aimed in this study to analyze the efficacy of garlic extract against the viability of $E$. faecalis from clinical isolates of nonvital primary root canals.
\end{abstract}

Methods: We used MTT assay to determine the viability of E. faecalis after exposure to increasing concentrations of garlic extract $(10 \%, 25 \%, 50 \%$, and $100 \%$ ) and chlorhexidine (CHX) $2 \%$ as a positive control.

Results: We performed the analysis using the Kruskal-Wallis test and the post hoc test for multiple comparisons at a 0.05 significance level. At all concentrations, garlic extracts decreased the viability of E. faecalis. We found no significant differences between the viability values for $25 \%, 50 \%$, and $100 \%$ garlic extracts ( $p>0.05)$; however, they were significantly different from the $10 \%$ extract and CHX $2 \%$ ( $<<0.05$ ), both with a lower viability values.

Conclusion: Our results showed that garlic extract was effective in decreasing the viability of $E$. faecalis.

Keywords: Garlic extract, viability, Enterococcus faecalis.

(C) 2019 The Authors. Published by Innovare Academic Sciences Pvt Ltd. This is an open access article under the CC BY license (http://creativecommons. org/licenses/by/4. 0/) DOI: http://dx.doi.org/10.22159/ijap.2019.v11s1.17351

\section{INTRODUCTION}

Allium sativum, or garlic, is a plant proven to have drug efficacy and to possess antibacterial, antifungal, and antiviral properties. Garlic extract reportedly has antibacterial effects against a wide range of bacteria, including Escherichia coli, Salmonella enteric, Shigella, Enterococcus faecalis, Staphylococcus aureus, Streptococcus (S. faecalis, S. mutans, and S. pyogenes), Klebsiella aerogenes, Pseudomonas aeruginosa, and Proteus vulgaris. The crushing or chopping of cloves of garlic releases their antibacterial activity, which derives from the allicin compound through the enzymatic activity of alliinase (cysteine sulfoxide lyase) in alliin. Allicin and other thiosulfinates are believed to be associated with the therapeutic effects of garlic [1-3]

Root canal infections of primary teeth, whether symptomatic or asymptomatic, are caused by microbes found in the root canal. The microorganisms found in the root canals of primary teeth, like those of the permanent dental root, are aerobic and nonaerobic bacteria and facultative bacteria [4,5]. da Silva et al. found aerobic and anaerobic microorganisms, black-pigmented bacilli, Streptococci, and Gramnegative aerobic rods in the root canals of nonvital primary teeth [6]. Other studies found Enterococcus spp. and Porphyromonas gingivalis to be the predominant bacteria found in the root canals of nonvital primary teeth $[4,7]$. E. faecalis were anaerobic facultative Grampositive bacteria with powerful virulence factors including the ability to compete with other microorganisms, invade the dentinal tubules, and survive nutritional deficiencies. Adhering to the root canal walls, accumulating to form biofilms, and so becoming more resistant to irrigation substances and Intracanal medicaments, they were consequently often associated with persistent infections and root canal treatment failures [8-10].
Root canal treatments conducted in primary teeth are intended to preserve them until exfoliation and replacement by permanent teeth. Root canal clearance of primary teeth aims to remove the necrotic tissue as far as possible in the root canal without disturbing the emergence of the permanent tooth buds [11], a process known as a chemomechanical preparation, an active chemical solution or irrigation solution used in conjunction with mechanical instrumentation in the root canal. Most microorganisms present in root canal infections of primary teeth were found in the apical ramifications and dentinal tubules [5]. Because the infected primary teeth, as with the permanent teeth, could store microorganisms in the dentinal tubule, the use of chemicals was required to help disinfect the area. Throughout the instrumentation, irrigation solutions could remove necrotic and contaminated materials, disinfect the root canals and dentinal tubules, and eliminate bacteria [12]. Commonly used root canal irrigants include sodium hypochlorite $(\mathrm{NaOCl})$, chlorhexidine $(\mathrm{CHX})$, and other chemicals that could have a toxic effect on the periapical tissues and permanent tooth buds when pushed to the apex [5].

The increased resistance to antibiotics of microbes and toxicity of antimicrobial agents has engendered a need for alternative, nontoxic, effective, and readily available agents. Many natural plant extracts could be applied as effective root canal irrigation solutions. The main advantages of herbal irrigants are their safety, ready availability, durability, cost-effectiveness, and, to date, lack of evidence of bacterial resistance [12]. Several in vitro studies had shown that herbal plants, one of which is the extract of garlic (A. sativum), possess promising properties as antibacterial agents, as evidenced by several in vitro studies. We aimed in our study to analyze the efficacy of garlic extract at various concentrations against the viability of $E$. faecalis obtained from the clinical isolates of nonvital primary root canals. 


\section{METHODS}

Our laboratory experimental study comprised sample collection, E. faecalis isolation, preparation of garlic extract, viability tests with MTT assay, and statistical analysis.

\section{Sample collection}

We enrolled patients aged 4-8 years who attended the pediatric dental clinic of Universitas Indonesia and were diagnosed with nonvital primary tooth due to caries with or without periapical infection. The Ethics Committee of the Faculty of Dentistry, Universitas Indonesia, approved all clinical procedures. Before the commencement of the study, we obtained informed consent from each parent/guardian, together with a detailed medical and dental history. We excluded patients who had received antibiotic therapy in the past 3 months, or were suffering from a systemic disease, from this study. We included patients who fulfilled the criteria of patient and parent cooperation, teeth with intact roots or $<1 / 3$ of physiological root resorption, no root canal intervention prior to the study, no root canal obliteration, and the remaining crown allowing isolation with a rubber dam and further restoration.

To ensure antisepsis of the oral cavity, patients rinsed for 1 min with $10 \mathrm{~mL}$ of $0.12 \%$ CHX; we then placed a rubber dam. After the removal of carious tissue, we accessed the root canal with high-speed sterile diamond burs. We collected samples with a sterile \#15 K-file to agitate canal contents for $60 \mathrm{~s}$. We introduced the file to a level approximately $1 \mathrm{~mm}$ short of the tooth apex based on the diagnostic radiographs, or to the limit of the physiological root resorption, and used a gentle filing motion. We than placed two sequential paper points to the same level and used them to soak up the fluid in the canal, holding each paper point in position for $60 \mathrm{~s}$. If the root canal was dry, we introduced a small amount of sterile saline solution into the canal to ensure viable sample acquisition. We never used chemically active irrigants before sampling. We then transferred the paper points and K-file to sterile Eppendorf tubes containing $1 \mathrm{~mL}$ of brain-heart infusion (BHI) broth. We stored the samples at $4^{\circ} \mathrm{C}$ before culture.

\section{Enterococcus faecalis isolation}

After shaking the tubes containing samples in a vortex mixer, we transferred $50 \mu \mathrm{L}$ and plated it on the Chromagar plates, which we incubated under anaerobic condition at $37^{\circ} \mathrm{C}$ for $24 \mathrm{~h}$. Having confirmed the culture visually, we transferred it to $7 \mathrm{~mL} \mathrm{BHI}$ broth by taking one colony of bacteria from the Chromagar plate. We then incubated the plates under anaerobic conditions at $37^{\circ} \mathrm{C}$ for $24 \mathrm{~h}$. We extracted the bacterial DNA from E. faecalis and performed DNA amplification by conventional polymerase chain reaction (PCR). The primer pair used to detect $E$. faecalis was $5^{\prime}$ TACTGACAAACCATTCATGATG $3^{\prime}$ forward and 5'AACTTCGTCACCAACGCGAAC $3^{\prime}$ reverse. We performed amplification with a thermal cycle as follows: denaturation at $94^{\circ} \mathrm{C}$ for $15 \mathrm{~min}, 40$ cycles of denaturation at $94^{\circ} \mathrm{C}$ for $20 \mathrm{~s}$, annealing at $68^{\circ} \mathrm{C}$ for $45 \mathrm{~s}$, extension at $72^{\circ} \mathrm{C}$ for $15 \mathrm{~s}$, final phase at $72^{\circ} \mathrm{C}$ for $7 \mathrm{~min}$, and cooling phase at $4^{\circ} \mathrm{C}$. We conducted DNA identification by the electrophoresis process.

\section{Preparation of garlic extract}

We obtained garlic (A. sativum L.) from a traditional market in Jakarta and used an extraction method based on Fujisawa et al. We crushed $40 \mathrm{~g}$ of garlic cloves with a utility garlic crusher and collected the juice and the debris of the garlic in a centrifuge tube, adding $40 \mathrm{~mL}$ of solvent (ethanol 20\%). After shaking the tube for $30 \mathrm{~min}$, we allowed it to stand for $10 \mathrm{~min}$ at room temperature and then centrifuged it at $9000 \mathrm{rpm}$ for $10 \mathrm{~min}$, after which we filtered the garlic juice with filter paper to separate the supernatant. To achieve concentrations of $10 \%, 25 \%$, and $50 \%$, we diluted the extract with sterilized distilled water.

\section{Viability test using MTT assay}

We homogenized the E. faecalis samples in BHI broth in a vortex mixer and added $100 \mu \mathrm{L}$ of bacteria suspension to each well in a 96-well microplate, which we then covered with a lid and incubated under anaerobic condition at $37^{\circ} \mathrm{C}$ for $24 \mathrm{~h}$. Then, we rinsed each well with sterile phosphate-buffered solution (PBS). We proceeded to expose the E. faecalis biofilm to $100 \mu \mathrm{L}$ of garlic extract at different concentrations and $2 \% \mathrm{CHX}$ as a positive control. We also prepared a negative control (medium only). We sealed the microplate and incubated it under anaerobic condition at $37^{\circ} \mathrm{C}$ for $24 \mathrm{~h}$. After incubation with garlic extract, we rinsed each well with sterile PBS and added $50 \mu \mathrm{L}$ of MTT solution $(5 \mathrm{mg} / \mathrm{mL})$ to the experimental wells, covered the plate with aluminum foil to attain a dark environment, and incubated it under anaerobic conditions at $37^{\circ} \mathrm{C}$ for $3 \mathrm{~h}$. Then, we added $100 \mu \mathrm{L}$ of acidified isopropanol to each experimental well and placed them on an orbital shaker at $50 \mathrm{rpm}$ for $1 \mathrm{~h}$. We read the absorbance value using an enzyme-linked immunosorbent assay reader with a wavelength of $490 \mathrm{~nm}$. We used the optical density of the treatment and control groups in the following formula to calculate the cell viability percentage score:

\section{$\frac{\text { ODtreatment }}{\text { ODnegativecontrol }} \times 100 \%$}

Statistical analysis

We tested all results by the Kruskal-Wallis statistical test with a significance level of $\mathrm{p}<0.05$.

\section{RESULTS}

We obtained clinical samples from nonvital primary root canals. We detected E. faecalis from the presence of greenish-blue colonies in selective chromogenic medium and white bands obtained through the electrophoresis test using the conventional PCR method. We performed the statistical analysis using the Kruskal-Wallis test to analyze the difference in the viability value of E. faecalis against garlic extract at various concentrations.

Table 1 shows a decrease in the viability value of E. faecalis with the increase in garlic extract concentration. The Kruskal-Wallis test indicated that the viability values of at least two groups differed significantly. We conducted a post hoc Mann-Whitney test to identify the differences between treatment groups.

Table 2 shows the post hoc analysis results demonstrating statistically significant differences with regard to the viability values of $E$. faecalis between the negative control group versus the positive control and the entire garlic extract concentration group; the positive control versus groups of $25 \%, 50 \%$, and $100 \%$ garlic extract; and the group of $10 \%$ garlic extract versus groups of $25 \%, 50 \%$, and $100 \%$ garlic extract. However, we found no significant differences between the groups of $25 \%, 50 \%$, and $100 \%$ garlic extract

Table 1: Viability values of Enterococcus faecalis after administration of garlic extract at various concentrations

\begin{tabular}{lll}
\hline Treatment group & $\mathbf{n}$ & Viability (\%) Median (minimum-maximum) \\
\hline Negative control & 5 & $60.88(54.12-191.24)$ \\
Positive control (2\% CHX) & 5 & $28.52(24.18-30.17)$ \\
$10 \%$ garlic extract & 5 & $16.73(13.35-44.70)$ \\
$25 \%$ garlic extract & 5 & $5.17(4.94-7.45)$ \\
$50 \%$ garlic extract & 5 & $4.71(3.89-7.27)$ \\
$100 \%$ garlic extract & 5 & $4.62(4.21-6.17)$ \\
\hline
\end{tabular}

Kruskal-Wallis analysis: *Significance level based on $\mathrm{p}<0.05$ 
Table 2: Post hoc analysis of viability values of Enterococcus faecalis in various concentrations of garlic extract

\begin{tabular}{lllllll}
\hline \multirow{2}{*}{ Test material } & \multicolumn{2}{l}{ Garlic extract } & & & \multirow{2}{2}{ \% CHX } & Negative control \\
\cline { 2 - 5 } & $\mathbf{1 0 \%}$ & $\mathbf{2 5 \%}$ & $\mathbf{5 0 \%}$ & $\mathbf{1 0 0 \%}$ & & $0.009^{*}$ \\
\hline 10\% garlic extract & & $0.009^{*}$ & $0.009^{*}$ & 0.295 & $0.009^{*}$ \\
25\% garlic extract & 0.009 & & 0.347 & 0.347 & $0.009^{*}$ & $0.009^{*}$ \\
50\% garlic extract & $0.009^{*}$ & 0.347 & & 0.917 & $0.009^{*}$ & $0.009^{*}$ \\
100\% garlic extract & $0.009^{*}$ & 0.347 & 0.917 & & $0.009^{*}$ & $0.009^{*}$ \\
2\% CHX & 0.295 & $0.009^{*}$ & $0.009^{*}$ & $0.009^{*}$ & & $0.009^{*}$ \\
Negative control & $0.009^{*}$ & $0.009^{*}$ & $0.009^{*}$ & $0.009^{*}$ & $0.009^{*}$ & \\
\hline
\end{tabular}

Post hoc Mann-Whitney analysis. *Significance level based on $\mathrm{p}<0.05$. CHX: Chlorhexidine

\section{DISCUSSION}

We conducted this study to analyze the effectiveness of garlic extract against the viability of $E$. faecalis from clinical isolates. Our detection of E. faecalis in the primary teeth corresponded to a study that found $E$. faecalis to be the most common bacterium found in the root canals of nonvital deciduous teeth [7]. Enterococcus is a Gram-positive bacterium that may appear individually, in pairs, or as a type of facultative anaerobic bacteria (having the ability to grow in existing conditions and without oxygen) in a short-chain form. These bacteria were considered to be normal microbes commonly found in individuals and located principally in the digestive tract, female organs, and, at a lower frequency, the oral cavity. Only in recent years, E. faecalis has become a focus in health and dentistry. E. faecalis virulence factors include a lysis enzyme, cytolysin, aggregate substance, pheromone, and lipoteichoic acid. These factors influence the adhesion to the host cell, the release of proteins to compete with other bacteria, and altered host response. The persistence of E. faecalis located in the root canals is due to the presence of proteinases, gelatinases, and collagen proteins that enhance dentine bonds. These bacteria can survive for long periods in conditions of starvation until adequate nutrition becomes available. E. faecalis adheres to the root canal walls, accumulates, and forms biofilms, such that the bacteria are 1000 times more resistant than planktonic forms to phagocytosis, antibodies, and antimicrobials [8-10]. The ability of E. faecalis to form biofilms causes resistance to some commonly used irrigation solutions and intracanal medicaments [10].

As the antibacterial test in this study, we used the MTT assay. We used the popular method to estimate the metabolic activity of living cells. This test is based on the enzymatic reduction of a lightcolored tetrazolium salt into a purple-bluish, spectrophotometrically quantifiable formazan. The absorbance value obtained is proportional to the number of living cells. The MTT assay could serve as one of the antibacterial test methods and could be an alternative or additional method for determining minimum inhibitory concentration, that is, the lowest concentration able to withstand bacterial growth. This method avoided interference with the results by dead bacterial cells. The MTT assay could also serve as an alternative method of microbial biofilm quantification. Unlike crystal violet staining, MTT made it possible to localize and quantify bacteria, particularly living cells [13].

Our results implied that various concentrations of garlic extract effectively reduced the number of viable E. faecalis bacteria in vitro. The highest viability value was found in the $10 \%$ garlic extract. This accorded with a previous study confirming the weak antibacterial effect of $10 \%$ garlic extract against E. faecalis [14]. According to Lee et al., the minimum inhibition rate of garlic extract against the growth of E. faecalis was $12.8 \%$; this accounted for the limited antibacterial efficacy of the $10 \%$ garlic extract in reducing the viability of E. faecalis [15]. Our results, in accordance with previous studies, demonstrated that the viability value would decrease with increasing concentrations [14,15]. The antibacterial activity of garlic resided in the allicin compound through the enzymatic activity of alliinase (cysteine sulfoxide lyase) in alliin after crushing or chopping cloves of garlic [1-3]. Allicin inhibited RNA synthesis and partially inhibited DNA and protein synthesis. The inhibition or limiting of RNA synthesis would greatly compromise protein synthesis, which would be halted during each stage due to the absence of mRNA, rRNA, and tRNA. Without the production of amino acids and proteins, the growth and development of the organism would not occur. Allicin would also affect lipid synthesis, thereby disturbing other parts of the cells. Principal among these effects would be that the phospholipid layers of Gram-positive and Gram-negative bacterial cell walls could not be properly formed [16].

We extracted the garlic using an unheated maceration method with $20 \%$ ethanol solvent. This was in accordance with previous literature, suggesting that the best way to extract garlic was to avoid the use of high temperatures, which were damaging to the allicin compound and deactivated other important compounds. Chavan stated that the therapeutic nature of garlic was destroyed through warming. Allicin was an unstable component formed from the enzymatic action of alliinase and discharged at temperatures above $65^{\circ} \mathrm{C}$ [15]. Allicin could be more efficiently extracted with ethanol solution than with water, but the levels decreased gradually at room temperature, and the majority of allicin disappeared within a few days, especially in 100\% ethanol and water. To maintain the allicin level for approximately 2 weeks at room temperature, the use of $20 \%$ ethanol as a solvent seemed to be more appropriate. In the process of extracting allicin from garlic, the use of ethanol solutions was considered preferable to water-based solutions. This was due to the hydrophobicity of allicin, which appeared more soluble in alcohol than in water. Ethanol also possessed hydroxyl groups of allicin stabilizers in the molecule [17].

In treating infected root canals, the root canal irrigants and medicaments used should have antimicrobial properties capable of disinfecting the root canal and additionally have no cytotoxic effect on periapical tissue and permanent tooth buds if pushed to the apex [10]. The addition of $2 \%$ CHX in the root canal treatment protocol could increase root canal disinfection [18]. CHX had a broad and effective antibacterial spectrum against Gram-positive, Gram-negative, fungal, and residual antibacterial effect $[12,18]$. However, by inhibiting protein synthesis and mitochondrial activities, CHX was highly cytotoxic to human periodontal ligament cells and harmed the fibroblast cells, where it also inhibited protein synthesis [19]. Our results implied that $25 \%$ garlic extract was effective in decreasing the viability of E. faecalis and was more effective than $2 \%$ CHX. Garlic extract, therefore, has great potential as an herbal root canal irrigant.

In this clinical study, we determined the efficacy of garlic extract as a root canal irrigant for primary teeth. Further studies are needed to maintain the stability of allicin in garlic extract to obtain a durable and optimal antibacterial effect.

\section{CONCLUSION}

Our study demonstrates that garlic extract is effective in decreasing the viability of E. faecalis obtained from clinical isolates of nonvital primary root canals.

\section{ACKNOWLEDGMENTS}

This study was fully supported and financed by the Directorate of Research and Community Service, Universitas Indonesia. 


\section{CONFLICT OF INTEREST}

The authors report no conflict of interest.

\section{REFERENCES}

1. Houshmand B, Mahjour F, Dianat O. Antibacterial effect of different concentrations of garlic (Allium sativum) extract on dental plaque bacteria. Indian J Dent Res 2013;24:71-5.

2. Mohammad SG, Baroudi K. Assessment of the potential of Allium sativum oil as a new medicament for non-vital pulpotomy of primary teeth. J Int Soc Prev Community Dent 2015;5:314-20.

3. Ili DP, Nikoli VD, Nikoli LB, Stankovi MZ, Stanojevi LP, Caki MD. Allicin and related compounds: Biosynthesis, synthesis and pharmacological activity. FUPhys Chem Tech 2011;9:9-20.

4. Rana V, Baba SM, Pandey A. Bacteriology of infected deciduous root canal-A review abstract : Introduction . People's J Sci Res 2009;2:45-8.

5. Ramachandra JA, Nihal NK, Nagarathna C, Vora MS. Root canal irrigants in primary teeth. World J Dent 2015;6:229-34.

6. da Silva LA, Nelson-Filho P, Faria G, de Souza-Gugelmin MC, Ito IY. Bacterial profile in primary teeth with necrotic pulp and periapical lesions. Braz Dent J 2006; 17:144-8.

7. Fabris AS, Nakano V, Avila-Campos MJ. Bacteriological analysis of necrotic pulp and fistulae in primary teeth. J Appl Oral Sci 2014;22:118-24.

8. Stuart CH, Schwartz SA, Beeson TJ, Owatz CB. Enterococcus faecalis : Its role in root canal treatment failure and current concepts in retreatment. J Endod 2006;32:93-8.

9. John G, Kumar KP, Gopal SS, Kumari S, Reddy BK. Enterococcus faecalis, a nightmare to endodontist: A systematic review. Afr J Microbiol Res 2015;9:898-908.
10. Bo D, Kayombo CM. Effect of nanosilver gel, chlorhexidine gluconate, and camphorated phenol on Enterococcus faecalis biofilm. Int Sch Res Notices 2014;2014:380278.

11. Casamassimo PS, Fields HW, McTigue DJ, Nowak AJ. Pediatric Dentistry: Infancy through Adolescence. $5^{\text {th }}$ ed. St. Louis, Missouri: Elsevier; 2013

12. Kaur R, Singh R, Sethi K, Garg S, Miglani S. Review article irrigating solutions in pediatric dentistry: Literature review and update. J Adv Med Dent Sci Res 2014;2:104-15.

13. Grela E, Kozłowska J, Grabowiecka A. Current methodology of MTT assay in bacteria - A review. Acta Histochem 2018;120:303-11.

14. Salih JM, Monawer AT, Abdullkahar IM. Antibacterial activity of garlic against multi-drug resistant Staphylococcus aureus and Enterococcus faecalis in Duhok City. J Univ Duhok 2016;19:114-22.

15. Birring OJ, Viloria IL, Nunez P. Anti-microbial efficacy of Allium sativum extract against Enterococcus faecalis biofilm and its penetration into the root dentin: An in vitro study. Indian J Dent Res 2015;26:477-82.

16. Durairaj S, Srinivasan S, Lakshmanaperumalsamy $\mathrm{P}$. In vitro antibacterial activity and stability of garlic extract at different ph and temperature. Electron J Biol 2009;5:5-10.

17. Fujisawa H, Suma K, Origuchi K, Kumagai H, Seki T, Ariga T, et al. Biological and chemical stability of garlic-derived allicin. J Agric Food Chem 2008;56:4229-35.

18. Mohammadi Z, Jafarzadeh H, Shalavi S. Antimicrobial efficacy of chlorhexidine as a root canal irrigant: A literature review. J Oral Sci 2014:56:99-103.

19. Chang YC, Huang FM, Tai KW, Chou MY. The effect of sodium hypochlorite and chlorhexidine on cultured human periodontal ligament cells. Oral Surg Oral Med Oral Pathol Oral Radiol Endod 2001;92:446-50. 